\title{
MEASUREMENT OF ELECTRON DENSITY IN ATMOSPHERIC PRESSURE ARGON GLOW DISCHARGE
}

\author{
R. B. Tyata ${ }^{1,2}$, D. P. Subedi ${ }^{2}$ \\ ${ }^{1}$ Department of Electrical, Khwopa College of Engineering, Libali-2, Bhaktapur, Nepal \\ ${ }^{2}$ Department of Natural Science, Kathmandu University, Dhulikhel, Nepal
}

\begin{abstract}
In this report, an atmospheric pressure glow discharge (APGD) in argon has been investigated by means of electrical measurement using parallel plate electrodes. The discharge was produced by passing argon gas at controlled flow rate of $1 \mathrm{lit} / \mathrm{min}$, with dielectric barrier of glass between the electrodes. The inter-electrode spacing was varied from $1 \mathrm{~mm}$ to $3 \mathrm{~mm}$. The electrical measurement of the discharge showed that there exists only one current pulse per half cycle in the current waveform indicating the formation of glow discharge. Power balance method was applied for the determination of electron density. Our results showed that the electron density in the discharge is of the order of $10^{10} \mathrm{~cm}^{-3}$ with $26 \mathrm{kHz}$ frequency of high voltage power supply.
\end{abstract}

Keywords: $A P G D$, Argon, electron density.

\section{Introduction}

Dielectric barrier discharge (DBD) and glow discharge in atmospheric pressure have been well known from few decades due to its wide applications in industry, environment and medicine (Balcon et al., 2006; Kogleschatz, 2003). The interest of DBD and atmospheric pressure glow discharge (APGD) have been emphasized in practical application because it minimizes the needs for vacuum systems and enables the handling of the bulky materials in continuous process. The advantage of APGD in comparison to filamentary DBD will be the uniformity of plasma which is important for deposition of uniform thin films and surface treatment of materials (Massines et al., 1998).

In general, a stable glow discharge is found only in a low pressure discharge of less than few mbar (Nozaki \& Okazaki, 2006; Okazaki et al., 1993). Atmospheric pressure glow discharge is normally unstable and it tends to change to a filamentary discharge, very dependent on the specific gas, the material of dielectric barrier, the structure of the

*Corresponding author: R. B. Ty ata

Department of Electrical, Khwopa College of Engineering,

Libali-2, Bhaktapur, Nepal

Email: rbtyata@y ahoo.com

(Received: 2013 Jan 02 Accepted: 2013 Mar 03) discharge electrode, the frequency, the electrode spacing and the humidity of gas (Park et al., 2000; Subedi et al., 2009).

In this paper, we report the production of APGD in argon and its electrical characterization. We have also measured the electron density in the discharge by power balance method.

\section{Experimental Setup}

The schematic diagram of experimental arrangement used to study the APGD is shown in Fig 1. The discharge is generated between two parallel electrodes. Instead of getting glow type of discharge, we get filamentary, arc, corona or any other type of discharge, if the electrode surface is rough and with sharp edges. This is due to the action of point as the electric charges are concentrated at sharp points and edges. To avoid such type of potentially coming problems to get glow type of discharge, parallel discs with smooth surfaces have been used as electrodes. It consists of two identical discs of brass with diameter $5.05 \mathrm{~cm}$ and thickness $1.02 \mathrm{~cm}$ held parallel one above another. The lower plate is fixed, and the upper plate is movable with pitch of $0.5 \mathrm{~mm}$. Glass plate of thickness $1 \mathrm{~mm}$ was used as a dielectric barrier. 


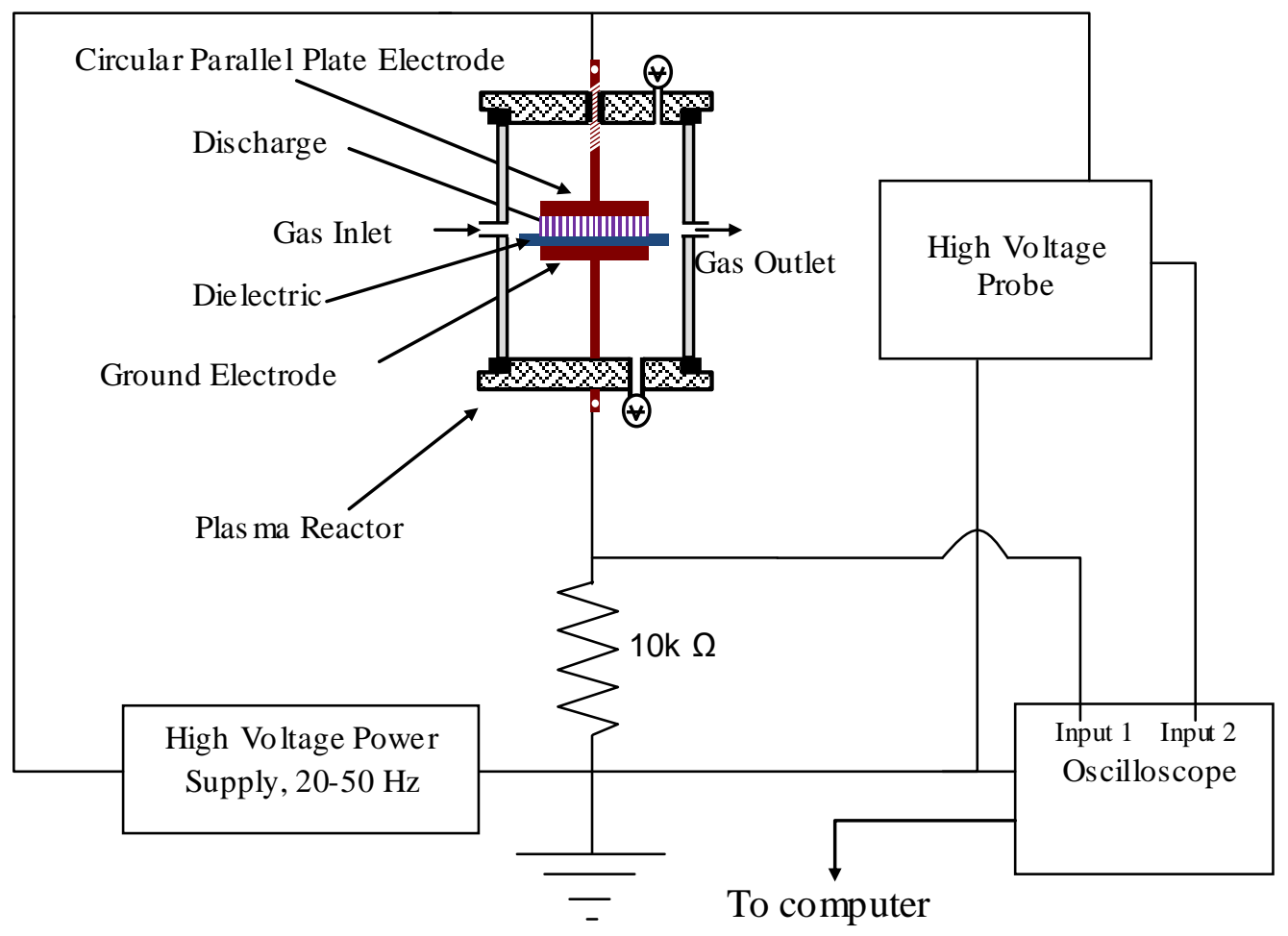

Fig 1 Schematic diagram of experimental setup.

A high voltage AC power supply was used and the applied voltage was in the range of 1 to $2 \mathrm{kV}_{r m s}$ at a frequency $26 \mathrm{kHz}$. The gap between the electrodes was varied from $1 \mathrm{~mm}$ to $3 \mathrm{~mm}$ and flow of argon was set to 1 liter per minute. Electrical characterization was made with the help of a high voltage probe using Tektronix TDS2002 digital oscilloscope.

\section{Result and Discussion}

\subsection{Electrical Cha racterization}

The voltage and current waveforms of the discharge obtained with electrode spacing of $1 \mathrm{~mm}, 2 \mathrm{~mm}$ and $3 \mathrm{~mm}$ are shown in Figs. 2, 3 and 4 respectively. The waveforms are nearly sine wave which indicates the formation of glow like discharge.

In this experiment, the voltage of AC power supply applied to the electrodes has been manually increased very slowly in the presence of argon flowing (1 liter per min). When the voltage $\left(\mathrm{V}_{\mathrm{pp}}\right)$ was increased to $1.6 \mathrm{kV}$ with $1 \mathrm{~mm}$ of electrode gap, glow discharge was obtained in the entire electrode space. The current waveform was slightly distorted in $0.7 \mathrm{~mA}$ amplitude and then current peak rose up to $1 \mathrm{~mA}$ in amplitude. One current pulse was found in one half cycles. For $2 \mathrm{~mm}$ of electrode spacing, the glow discharge was obtained with an applied voltage of $1.8 \mathrm{kV}$, but the current waveform was distorted in $0.8 \mathrm{~mA}$ and pulse reached up to $1.3 \mathrm{~mA}$.

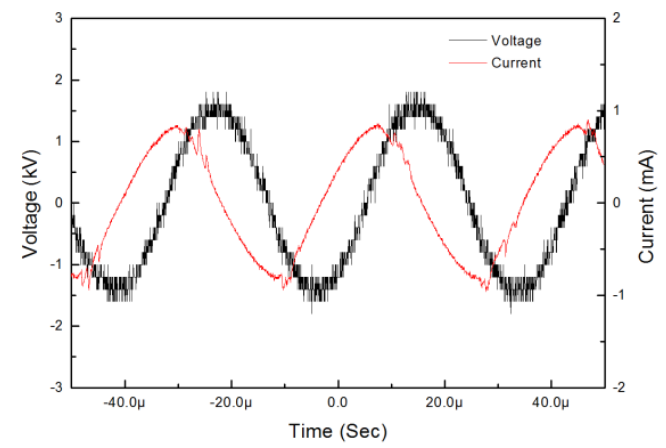

Fig 2 Voltage and current waveforms of the APGD produced with electrode spacing $1 \mathrm{~mm}$. 


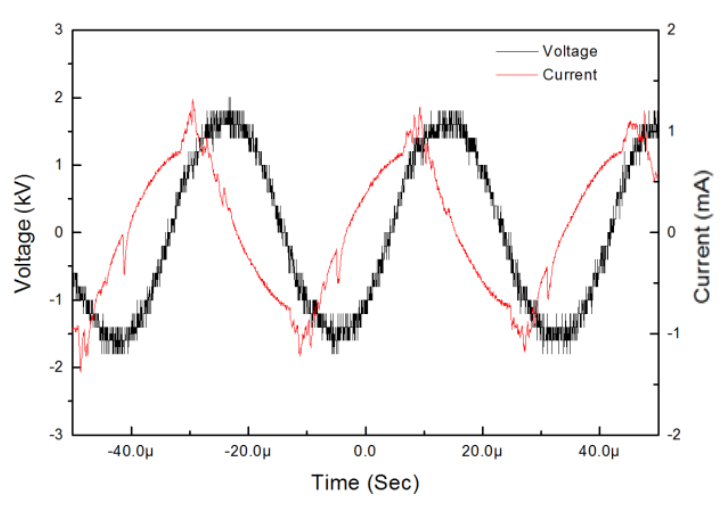

Fig 3 Voltage and current waveforms of APGD produced with electrode spacing $2 \mathrm{~mm}$.

In the same way for $3 \mathrm{~mm}$ of electrode spacing, the glow discharge was obtained with an applied voltage of $2 \mathrm{kV}$ while the current waveform was found to be distorted in $1.6 \mathrm{~mA}$. The appearance of only one spike per half cycle is an indication of the formation of glow discharge.

\subsection{Estimation of Electron Density}

The electron density can be obtained by the relation of power balance method,

$$
\mathrm{n}_{\mathrm{e}}=\frac{\mathrm{p}_{\mathrm{av}}}{2 \mathrm{AV}_{\mathrm{b}} \mathrm{E}_{\text {lost }}}
$$

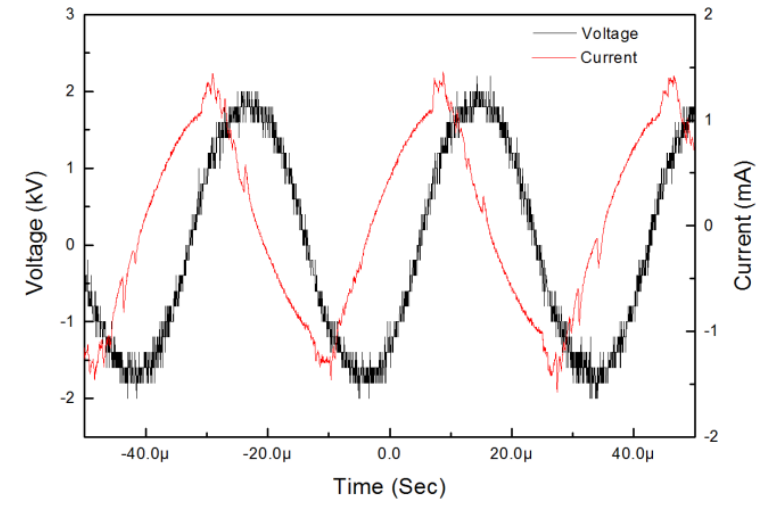

Fig 4 Voltage and current waveforms of APGD produced with electrode spacing of $3 \mathrm{~mm}$

where ne is electron density, average power (Pav) is 1.775 Watt (for Fig 2), area of electrode (A) is 20.03 $\mathrm{cm}^{2}$ and $\mathrm{V}_{\mathrm{b}}$ is $\mathrm{B}$ ohm velocity equal to ion acoustic velocity $\sim 2 \times 10^{5} \mathrm{cms}^{-1}$ and total energy lost by the plasma per electron-ion pair energy, Elost is $50 \mathrm{eV}$ [9]. From the voltage and current waveform analysis of Figs. 2-4, data of voltage and current for positive and two negative half cycles are tabulated in Table 1-3 respectively. Electron density of discharge in the case of electrode spacings of 1,2 and $3 \mathrm{~mm}$ were found to be $1.83 \times 10^{10} \mathrm{~cm}^{-3}$, $3.59 \times 10^{10} \mathrm{~cm}^{-3}$ and $4.34 \times 10^{10} \mathrm{~cm}^{-3}$ respectively.

Table 1 RMS voltage and current, average power and electron density of the discharge corresponding to the waveforms shown in Fig 2.

\begin{tabular}{|c|c|c|c|c|c|}
\hline S. N. & $\begin{array}{c}\text { Voltage Vrms } \\
(\mathrm{kV})\end{array}$ & $\begin{array}{c}\text { Discharge } \\
\text { Current } \\
\text { Irms }(\mathrm{mA})\end{array}$ & $\begin{array}{c}\text { Power } \\
\text { Vrms } \times \text { Irms (Watt) }\end{array}$ & $\begin{array}{c}\text { Average power } \\
\mathrm{P}(\text { Watt })\end{array}$ & $\begin{array}{c}\text { Electron density } \\
\mathrm{n}_{\mathrm{e}}\left(\mathrm{cm}^{-3}\right)\end{array}$ \\
\hline 1 & 1.41 & 0.90 & 1.27 & \multirow{2}{*}{1.17} & \multirow{2}{*}{$1.83 \times 10^{10}$} \\
\hline 2 & 1.40 & 0.85 & 1.19 & 1.05 & \\
\hline 3 & 1.40 & 0.75 & & \\
\hline
\end{tabular}

Table 2 RMS voltage and current, average power and electron density of the discharge corresponding to the waveforms shown in Fig 3.

\begin{tabular}{|c|c|c|c|c|c|}
\hline S. N. & $\begin{array}{c}\text { Voltage Vrms } \\
(\mathrm{kV})\end{array}$ & $\begin{array}{c}\text { Discharge } \\
\text { Current } \\
\text { Irms }(\mathrm{mA})\end{array}$ & $\begin{array}{c}\text { Power } \\
\text { Vrms } \times \text { Irms (Watt) }\end{array}$ & $\begin{array}{c}\text { Average power } \\
\mathrm{P}(\text { Watt })\end{array}$ & $\begin{array}{c}\text { Electron density } \\
\mathrm{n}_{\mathrm{e}}\left(\mathrm{cm}^{-3}\right)\end{array}$ \\
\hline 1 & 1.80 & 1.40 & 2.52 & \multirow{2}{*}{2.30} & $3.59 \times 10^{10}$ \\
\hline 3 & 1.75 & 1.30 & 2.28 & \\
\hline 3 & 1.75 & 1.20 & 2.10 & \\
\hline
\end{tabular}


Table 3 RMS voltage and current, average power and electron density of the discharge corresponding to the waveforms shown in Fig 4.

\begin{tabular}{|c|c|c|c|c|c|}
\hline S. N. & $\begin{array}{c}\text { Voltage Vrms } \\
(\mathrm{kV})\end{array}$ & $\begin{array}{c}\text { Discharge } \\
\text { Current } \\
\text { Irms }(\mathrm{mA})\end{array}$ & $\begin{array}{c}\text { Power } \\
\text { Vrms } \times \text { Irms (Watt) }\end{array}$ & $\begin{array}{c}\text { Average power } \\
\text { P (Watt) }\end{array}$ & $\begin{array}{c}\text { Electron density } \\
\mathrm{n}_{\mathrm{e}}\left(\mathrm{cm}^{-3}\right)\end{array}$ \\
\hline 1 & 1.90 & 1.50 & 2.85 & \multirow{2}{*}{2.78} & $4.34 \times 10^{10}$ \\
\hline 2 & 2.00 & 1.45 & 2.90 & 2.59 & \\
\hline 3 & 1.85 & 1.40 & & \\
\hline
\end{tabular}

\section{Conclusion}

An APGD in argon gas could be produced using high voltage power supply in circular parallel disc electrodes with different electrode gap. The electron density in the discharge is found to vary with the inter electrode spacing within the limit of our experimental range of the parameters. Our future work will concern on the generation of glow discharge in large volume and its application on polymer surface modification.

\section{Acknowledge ment}

This work was supported by the University Grants Commission (UGC), Sanothimi, Bhaktapur, Nepal.

\section{References}

[1] Balcon, N., Aanesland A., and Boswell R., 2006. IOP publishing Ltd., 16: 217-225, December.

[2] Garamoon A A. and El-zeer D M., 2009. Plasma Sources Sci. Technol., 18: 045006
[3] Kogleschatz U., 2003. Plasma Chem. Plasma Process., 23: 01-46

[4] Massines F., Rabehi A., Decomps Ph., Gadi R B., Segur P., Mayoux C., 1998. Journal of Applied Physics, $83: 2950-2957$.

[5] Nozaki T. and Okazaki K., 2006. Pure Appl. Chem., 78: 1157-1172

[6] Okazaki S., Kogoma M., Uehara M. and Kimura Y., 1993. J. Phys. D: Appl. Phys., 26: 889-92

[7] Park J., Henins I., Hermann H W., Selwyn G S., Jeong J Y., Hicks R F., Shim D., Chang CS., 2000. Appl Phys Lett,76: 288-290.

[8] Subedi D P., Tyata R B, Khadgi A. and Wong C S., 2009. Journal of Sci. and Technol. in the Tropics, $5: 117-123$

[9] Topper J., Lindmayer M. and Juttner B., 2000. XIII international Conf. on Gas Discharge and their Application, (Glasgow, Scotland, 03: 08 Setember 2000) 